\author{
Headspace 법을 사용한 유기농업자재 중 잔류 유기용매 분석 \\ 최근형 ${ }^{1} \cdot$ 공승헌 $^{2} \cdot$ 박병준 ${ }^{1} \cdot$ 문병철 ${ }^{1} \cdot$ 김진효 ${ }^{2, *}$ \\ 1농촌진흥청 국립농업과학원 화학물질안전과, ${ }^{2}$ 경상대학교 농업생명과학연구원 응용생명과학부(BK21 plus)
}

\title{
Analysis of Residual Organic Solvent in Environmentally-friendly Farming Materials with Headspace Method
}

\author{
Geun Hyoung Choi ${ }^{1}$, Seung-Heon Kong ${ }^{2}$, Byung-Jun Park ${ }^{1}$, Byeong-Cheol Moon ${ }^{1}$ and Jin-Hyo Kim ${ }^{2, *}$ \\ ${ }^{1}$ Chemical Safety Division, National Institute of Agricultural Sciences, RDA \\ ${ }^{2}$ Division of Applied Life Science (BK21 plus), Institute of Agriculture and Life Science (IALS), \\ Gyeongsang National University \\ (Received on May 24, 2016. Revised on June 11, 2016. Accepted on June 17, 2016)
}

\begin{abstract}
Volatile organic solvents are used to extract the bioactive materials from raw materials for environmentally-friendly farming materials (EFFM), but the solvent should not remain in EFFM for the safety reasons. Thus qualitative and quantitative analysis method for the solvents using Headspace-GC were evaluated. Water content depleted the detection ratio of hydrophilic solvents and disturbing the hydrophilic interaction with solvents by DMSO might be helped to increase the detection ratio (up to 715\%). Surfactant concentration affected to the detection ratio (68.5-179.1\%) while surfactant type was not deeply involved the solvent detection. On the other hand, matrix-matched calibration method was accepted the minimum requirements for the quantitative analysis of the solvents in EFFM.
\end{abstract}

Key words Detergent, Environmentally-friendly farming material, Headspace, Matrix-matched calibration, Organic solvent

유기농업자재는 지속가능한 농업의 구현과 작물생산량 보 전, 안전농산물 생산 그리고 유기농업 실천농가의 자재선택 편의를 도모하고자 유기농산물의 생산, 또는 취급하는 과정 에서 사용할 수 있는 제품으로서, ‘친환경농어업 육성 및 유 기식품 등의 관리·지원에 관한 법률'에서 허용하고 있는 물 질을 원료로 하여 만든 제품이다. 이러한, 유기농업자재는 공시제도와 품질인증제도를 통해 관리되고 있으며(Kim et al., 2015), 농촌진흥청에서는 고시 제2014-44호 '유기농업 자재 공시 및 품질인증 기준'의 제조공정 기준을 마련하여 유기농업자재에 대한 허용물질과 부자재 그리고 제조공정 등에 관해 엄격히 관리하고 있다. 특히 제조공정에 관한 규 정에서는 유기합성물질의 혼입과 최종 원료 중 잔류에 관한 규정을 두어, 유기합성물질로부터 유기농업자재 오염을 막 고 건강한 유기농산물의 생산에 기여하고 있다. 하지만, 병

*Corresponding author

E-mail:jhkim75@gnu.ac.kr
해충관리용 유기농업자재에 사용될 수 있는 유기합성용매 혹은 휘발성 물질에 대한 분석법이 마련되어 있지 않아, 유 기합성용매로 오염된 원료를 사용했는지 판별하기 쉽지 않 다. 특히, 휘발성이 강한 유기용매는 일반적인 추출, 정제방 법을 통해 오염여부를 분석하기 어려워, 식품, 의약품, 토양, 하천수 등에 대해서는 Headspace법과 GC-MSD를 사용하 여 분석하고 있다(Laus et al., 2009, Paik et al., 2011, Somuramasami et al., 2011, Urakami et al., 2004).

Headspace-GC 분석법은 휘발성 유기화학물질을 분석하 는데 가장 신속한 방법 중 하나로, 시료 중 기체상태로 휘발 된 물질을 $\mathrm{GC}$ 를 통해 분석하는 방법으로 알려져 있다. 따라 서, 분석물질의 기체상 분배상수 $\left(K=C_{\text {sample }} / C_{g a s}\right)$ 와 Phase ratio $(\beta)$ 에 따라 분석물질의 분석감도와 검출한계(LOD)가 결정되며, 이로 인해 동일 분석조건이라 하더라도 물질의 분배상수가 작을수록 검출한계가 낮고, 높은 온도에서 낮은 분배상수를 갖는다(Kolb et al., 1992, Ettre et al., 1993). 또한, 
시료 내 무기염 농도를 증가시키면 이온세기(I)가 증가함에 따라 극성 유기물질의 용해도는 낮아지게 되어 matrix effect 감소에 의한 극성유기물질의 $K$ 값을 개선하게 된다 (Ye et al., 2006, Teja et al., 2001). 이러한 matrix effect는 비휘발성 극성 유기용매인 $N, N$-Dimethylformamide (DMF) 혹은 Dimethyl sulfoxide (DMSO) 등의 시료 내 농도에 따 라 달라지기도 하며(Laus et al., 2009), 두 종 이상의 휘발성 물질이 존재할 경우 Henrey의 법칙과 Raoult의 법칙에 따라 분자간 친화력에 따른 mole fraction ratio값이 vapor pressure 에 영향을 주어 각 성분별 정량 분석능이 시료에 따라 달라 질 수 있는 문제점을 안고 있다(Laus et al., 2009, Urakami et al., 2004). 이로 인해 동일 공정을 통해 생산되는 제품 혹 은 하천수와 같은 비교적 단순한 matrix로 구성된 시료의 경우 Headspace 분석법을 통해 휘발성물질의 정량분석이 가능하지만, 계면활성제 등 여러 보조제가 함유된 복잡한 matrix를 갖는 유기농업자재는 정성분석으로의 접근이 적합 할 것으로 판단되었다. 따라서, 본 연구에서는 Headspace 법을 활용한 유기용매 분석에서 시료에 포함된 수분 제어에 따른 극성유기용매의 분석능 변화도를 관찰하고, 병해충관 리용 유기농업자재로 빈번히 사용되는 계면활성제의 종류별 , 농도별 유기합성용매의 검출률을 평가하였다.

\section{재료 및 방법}

\section{시험재료}

시험에 사용된 분석대상 유기용매의 표준용액인 benzene, toluene, ethylbenzene, xylenes, acetone, dichloromethane, ethyl acetate, chloroform, hexane, DMSO는 reagent grade 를 Sigma-Aldrich Co. (St. Louis, MO, USA) 것을 사용하 였고, $\mathrm{DMSO}$ 를 사용하여 $100 \mathrm{mg} / \mathrm{L}$ 로 희석하여 사용하였다. Tween ${ }^{\circledR}$ 20, Tween ${ }^{\circledR}$ 80, Kolliphor ${ }^{\circledR}$ EL은 Sigma-Aldrich Co. (St. Louis, MO, USA)에서, PEG2000과 PEG6000은 Junsei Chemical Co. (Tokyo, Japan) 것을 사용하였고, 유기 농업자재는 지역판매상에서 유통 중인 제품을 사용하였다.

\section{기기분석}

시험은 Headspace GC-MSD를 사용하여 DB-5MS capillary column을 사용하여 분석하였다(Table 1).

\section{Headspace 시료준비}

Headspace sampler 내 분석대상 물질과 혼합된 matrix 조 건을 달리하여 휘발성 유기화학용매의 분석능을 GC-MSD 를 사용하여 평가하였으며, 이를 위해 사용된 시험조건은 Method I, III에서는 증류수 처리량을 달리하였고, Method II는 증류수 대신 포화식염수를 사용하였다. Method IV와 $\mathrm{V}$ 는 무수황산나트륨의 처리량을 달리하여 수분을 제거한 조건에서 각각 유기화학용매 상대검출량을 비교 평가하였다. Matrix 조성별 유기용매 검출능 평가 시험에 사용된 유기용 매 9종은 $\mathrm{DMSO}$ 에 용해시켜 각각 $10 \mathrm{mg} / \mathrm{L}$ 가 되도록 혼합 용액을 만들어 사용하였다. 보다 상세한 matrix 조성은 다음 과 같다. $20 \mathrm{~mL}$ Headspace vial에 증류수 $5 \mathrm{~mL}$, 시료용액 $0.5 \mathrm{~mL}$ 를 넣어 Method I의 분석에 사용하였고, 포화식염수

Table 1. Instrumental conditions, and qualitative and quantitative ions $(\mathrm{m} / \mathrm{z})$ of organic solvents on GC-MSD

\begin{tabular}{lll}
\hline Instrument & Agilent GC 6890N, Agilent 5973 MSD, Agilent 7694 HS sampler \\
\hline GC-Column & DB-5MS $(30 \mathrm{~m} \times 0.32 \mathrm{~mm}, 0.5 \mu \mathrm{m})$ & \\
\hline Oven condition & Initial $35^{\circ} \mathrm{C}($ holding $15 \mathrm{~min}) ;$ ramping $20^{\circ} \mathrm{C} / \mathrm{min}$ to $235^{\circ} \mathrm{C}$ (holding $\left.1 \mathrm{~min}\right)$ \\
\hline & HS oven temp. & $90^{\circ} \mathrm{C}$ \\
& Loop temp. & $95^{\circ} \mathrm{C}$ \\
& Transfer line temp. & $100^{\circ} \mathrm{C}$ \\
Head-Space condition & Equilibration time & $15 \mathrm{~min}$ \\
& Shake & Low \\
& GC cycle & $35 \mathrm{~min}$ \\
& Pressurization time & $0.2 \mathrm{~min}$ \\
Non-polar solvents & Vent(loop fill) time & $0.2 \mathrm{~min}$ \\
Hexane & Injection time & $1.0 \mathrm{~min}$ \\
Ethyl acetate & Quantitative ions $(\mathrm{m} / \mathrm{z})$ & Qualitative ions $(\mathrm{m} / z)$ \\
Chloroform & 57 & 43 \\
Dichloromethane & 43 & 61 \\
Benzene & 83 & 85 \\
Toluene & 49 & 84 \\
Ethylbenzene & 78 & 52 \\
Xylenes $(o-, m-, p-)$ & 91 & 65 \\
Polar solvents & 91 & 106 \\
Acetone & 91 & 106 \\
\hline
\end{tabular}


Table 2. Summary of Headspace sample composition of each method

\begin{tabular}{lccccc}
\hline & \multicolumn{3}{c}{ Method } \\
\cline { 2 - 6 } & I & II & III & IV & V \\
\hline Organic solvents in DMSO (10 mg/L of each) & $0.5 \mathrm{~mL}$ & $0.5 \mathrm{~mL}$ & $0.5 \mathrm{~mL}$ & $0.5 \mathrm{~mL}$ & $0.5 \mathrm{~mL}$ \\
Distilled water & $5.0 \mathrm{~mL}$ & $0.5 \mathrm{~mL}$ & $0.5 \mathrm{~mL}$ & $0.5 \mathrm{~mL}$ & $0.5 \mathrm{~mL}$ \\
Saturated NaCl & - & $4.5 \mathrm{~mL}$ & - & - & - \\
Sodium sulfate (anhydrous) & - & - & - & $5.0 \mathrm{~g}$ & $10 \mathrm{~g}$ \\
\hline
\end{tabular}

Table 3. Average detection ratios of $10 \mathrm{mg} / \mathrm{L}$ organic solvent depending on extraction conditions*

\begin{tabular}{|c|c|c|c|c|c|}
\hline & \multicolumn{5}{|c|}{ Detection ratio $(\%)$} \\
\hline & Method I & Method II & Method III & Method IV & Method V \\
\hline \multicolumn{6}{|l|}{ Non-polar solvents } \\
\hline Hexane & 100.0 & 178.7 & 189.9 & 194.4 & 168.0 \\
\hline Ethyl acetate & 100.0 & 510.5 & 715.2 & 653.0 & 686.0 \\
\hline Chloroform & 100.0 & 189.9 & 200.7 & 185.1 & 194.4 \\
\hline Dichloromethane & 100.0 & 116.2 & 146.4 & 134.9 & 142.8 \\
\hline Benzene & 100.0 & 105.1 & 107.5 & 104.2 & 107.5 \\
\hline Toluene & 100.0 & 103.1 & 97.6 & 93.6 & 98.0 \\
\hline Ethylbenzene & 100.0 & 99.1 & 92.9 & 87.0 & 92.3 \\
\hline Xylenes $(o-, m-, p-)$ & 100.0 & 103.8 & 92.6 & 86.2 & 91.8 \\
\hline \multicolumn{6}{|l|}{ Polar solvents } \\
\hline Acetone & 100.0 & 165.5 & 481.5 & 446.6 & 441.3 \\
\hline
\end{tabular}

* All experiments were replicated three times and RSDs were below $12 \%$.

$5 \mathrm{~mL}$, 시료용액 $0.5 \mathrm{~mL}$ 를 사용하여 Method II의 분석용 시 료로 사용하였다. 그리고, 증류수 $0.5 \mathrm{~mL}$ 와 시료용액 0.5 $\mathrm{mL}$ 를 사용하여 Method III의 분석에 사용하였으며, $5 \mathrm{~g}$ 의 무수황산나트륨과 시료용액 $0.5 \mathrm{~mL}$, 증류수 $0.5 \mathrm{~mL}$ 를 사용 하여 Method IV의 분석에, $10 \mathrm{~g}$ 의 무수황산나트륨과 시료 용액 $0.5 \mathrm{~mL}$, 증류수 $0.5 \mathrm{~mL}$ 를 사용하여 Method $\mathrm{V}$ 의 분석 에 사용하였다(Table 2). 본 시험에 사용한 상대검출량은 Method I의 분석 결과값을 기준으로 산출하였다.

\section{결과 및 고찰}

시험에 사용된 유기용매는 산업용으로 많이 사용되면서, 유해물질로 지정된 benzene, toluene, ethyl benzene, xylenes (BTEX)를 포함하여, 추출물 제조에 많이 사용되는 acetone, chloroform, dichloromethane, ethyl acetate를 대상 으로 수행하였으며(Huie, 2002), 농자재에 사용이 허가된 ethanol 은 분석대상에서 제외하였다.

\section{Headspace matrix 조성별 휘발성 유기용매 분석능}

9종의 극성과 비극성 유기용매를 GC-MSD에서 분석한 결과, sampler 내 증류수 부피를 $10 \%$ 수준으로 줄일 경우 Method III의 분석결과에서 나타났듯이 비극성 유기용매인 hexane, chloroform, dichloromethane, benzene, toluene, ethylbenzene, xylenes의 상대 검출량은 $200 \%$ 이내로 상대 검출량이 증가함을 관찰하였다. 반면, ethyl acetate와 acetone 은 최대 $715 \%$ 까지 상대 검출량이 증가하였으며, 이는 분석 대상 물질의 용매로 사용된 DMSO의 molar ratio 증가로 인 해 물과 DMSO가 강한 hydrogen bond를 형성하기 때문에 vapor pressure 감소의 결과가 나타난 것으로 판단된다 (Luzar et al., 1993). Matrix내 DMSO 첨가에 따른 영향은 Belsky 등(2010)에 의해 보고된 바 있으며, 이는 본 시험결 과에서 나타난 결과와 같이 $\mathrm{DMSO}$ 의 molar ratio 증가가 hydrophilic functional group을 갖는 휘발성 물질의 분석감 도 향상에 도움을 주는 것과 일치하고 있다. 특히 이러한 결 과는 matrix내 이온세기를 증가시킨 Method II의 시험결과 에서도 유사한 경향을 나타내었다. 이러한 시험내용에 기초 하여 친수성기를 가진 용매의 검출감도를 높이기 위해 시료 의 수분을 제거하였을 때 분석감도의 변화를 비교하였다. 시험은 무수황산나트륨을 흡습제로 사용하여 각각 $5 \mathrm{~g}$ (Method IV)과 $10 \mathrm{~g}$ (Method V)을 처리하였으며, 시험결과 acetone과 ethyl acetate 등 친수성기를 가진 용매의 경우 분 석감도가 최대 6배까지 증가됨을 확인할 수 있었고, hexane 등 소수성기로만 구성된 용매의 분석감도는 큰 변화를 나타 내지 않았다(Table 3). 따라서, Headspace-GC법을 통해 유 
Table 4. Limit of detection (LOD) and linearity of organic solvents*

\begin{tabular}{lcc}
\hline & LOD $(\mathrm{mg} / \mathrm{L})$ & Linearity $($ range, $\mathrm{mg} / \mathrm{L})$ \\
\hline $\begin{array}{l}\text { Non-polar solvents } \\
\text { Hexane }\end{array}$ & 0.05 & $0.999(0.2-50)$ \\
Ethyl acetate & 0.02 & $0.999(0.2-50)$ \\
Chloroform & 0.02 & $0.999(0.2-50)$ \\
Dichloromethane & 0.10 & $0.999(0.2-50)$ \\
Benzene & 0.05 & $0.999(0.2-50)$ \\
Toluene & 0.05 & $0.999(0.2-50)$ \\
Ethylbenzene & 0.01 & $0.999(0.2-50)$ \\
Xylenes $(o-, m-, p-)$ & 0.01 & $0.999(0.2-50)$ \\
Polar solvents & & \\
Acetone & 0.35 & $0.999,0.5-50$ \\
\hline
\end{tabular}

* LOD and linearity were measured with Method III.

기용매를 분석할 때 친수성기를 가진 유기용매의 분석은 시 료 중 물의 간섭현상을 최대한 억제시키는 것이 분석감도 향상에 도움이 되는 것으로 판단되었다.

다양한 matrix 조건에서 수행된 시험결과를 바탕으로 가 장 높은 검출률을 나타낸 Method III을 기준으로 9종 유기 용매에 대한 limit of detection (LOD)와 linearity를 분석한 결과 $\mathrm{LOD}$ 는 $0.01-0.35 \mathrm{mg} / \mathrm{L}$ 로 확인되었으며, $0.2-50 \mathrm{mg} / \mathrm{L}$ 농도구간에서 $r^{2}$ 가 0.999 이상으로 양호한 직선성을 갖는 것 을 확인하였다(Table 4).

\section{Headspace법에서 계면활성제의 유기용매 검출 영향}

병해충관리용 유기농업자재에는 다양한 종류의 계면활성 제와 보조제 등이 사용되고 있으며, 이들 중 계면활성제는 유기용매의 분석감도에 중요한 영향을 미칠 수 있는 보조제 로 평가되고 있다. 따라서, 본 연구에서는 polysorbate계열 의 Tween ${ }^{\circledR}$ 을 대상으로 matrix내 함유량(5-50\%)을 달리하 여 유기용매 분석능 변화를 비교시험 하였다. 시험은 Method III과 같이 증류수 대신 계면활성제 시료용액 $0.5 \mathrm{~mL}$ 와 $10 \mathrm{mg} / \mathrm{L}$ 유기용매표준용액을 시료용기에 넣고 분석하였 다. Tween ${ }^{\circledR} 20$ 을 대상으로 한 시험에서 ethylbenzene과 xylenes의 경우 계면활성제 농도가 증가할수록 검출량이 다 소 감소하는 경향을 나타내었으며, hexane과 acetone은 다 소 증가하는 경향을 나타내었다(Fig. 1). 이러한 변화는 Tween ${ }^{\circledR} 80$ 에서도 같이 나타났다.

또한, polysorbate 계열의 계면활성제인 Tween ${ }^{\circledR}$ 외 oxyethylene 계열의 Kolliphor $($ 와 ethylene glycol 계열의 PEG2000과 PEG6000을 대상으로 계면활성제 $20 \%$ 조건에 서 유기용매 검출능을 시험한 결과 계면활성제 종류 차이에 따른 분석감도 변화는 $20 \%$ 이내로 관찰되었으며, 이는 Headspace를 사용한 잔류 유기용매 분석에서 계면활성제의 종류보다는 농도에 따라 분석능 변화가 크게 나타남을 확인

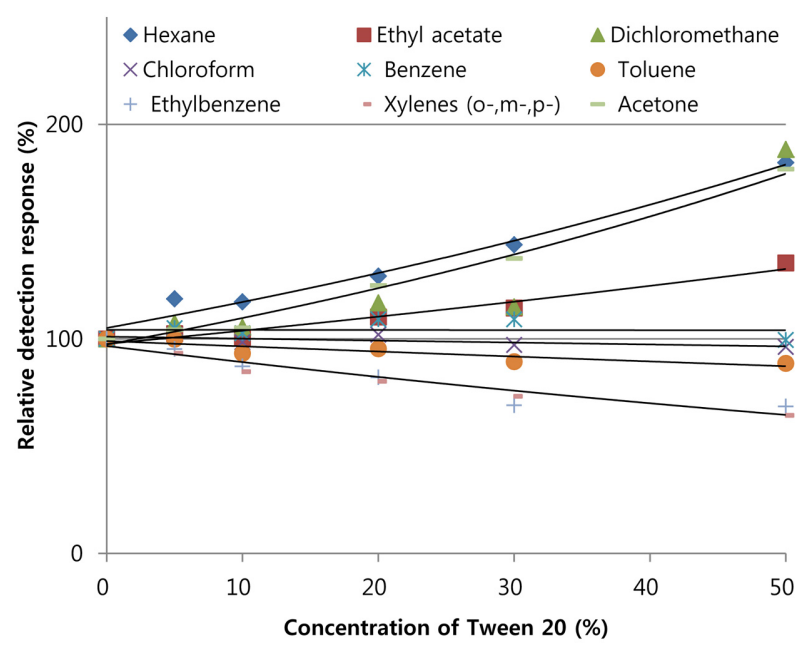

Fig. 1. Effect of relative solvent detection by surfactant concentration.

할 수 있었다. 이는 Headspace 용기내 계면활성제에 의해 생성된 micelle 농도에 따라 분석 대상성분의 검출능이 차 이가 크게 나타날 수 있음을 보고한 Jumepaeng 등(2012)의 결과와 유사한 결과로 판단되었다.

\section{유기농업자재 중 유기용매 정량분석}

병해충 관리용 유기농업자재는 다양한 종류의 계면활성제 가 사용되고 있으며, 계면활성제의 함량 또한 제조사 및 제 품에 따라 달라지고 있다. 이로 인해 다양한 matrix 조합을 갖는 유기농업자재에서 비의도적으로 포함될 수 있는 휘발 성 유기용매의 분석은 Headspace 법을 사용하여 정성분석 수행하는 것이 바람직할 것으로 판단된다. 하지만, 동일 matrix 조건을 갖추면 휘발성 유기용매의 정량분석이 Headspace법을 사용하여 가능할 것으로 예상되어 본 시험에서 개발된 분석조건(Method III)을 사용하여 유통 중인 식물추 출물을 활용한 액상 병해충관리용 유기농업자재 2종에 대해 9종의 유기용매를 대상으로 matrix-matched calibration $\left(\mathrm{r}^{2}\right.$ 0.998 이상)을 작성하고 이에 따른 회수율을 $10 \mathrm{mg} / \mathrm{L}$ 수준 에서 평가하였다. 시험결과 정량분석이 가능한 회수율을 (70-130\%) 나타내었으며, 분석시험간 $\mathrm{CV}$ 는 $8-11 \%$ 로 확인 되었다. 따라서, 시료마다 matrix-matched calibration 법을 적용하는 것이 매우 번거로운 과정으로 남아 있지만, 이러 한 과정을 통해 휘발성 유기용매의 정량분석이 가능할 것으 로 기대된다.

\section{감사의 글}

본 연구는 농촌진흥청 공동연구사업(과제번호: PJ01143505) 및 국립농업과학원 농업과학기술 연구개발사업(과제번호 : PJ010834)의 지원에 의해 수행되었습니다. 


\section{Literature Cited}

Belsky, J. L., A. J. Ashley, P. A. Bhatt, K. V. Gilbert, H. R. Joyce, C. Pan, H. Pappa and S. Z. Wahab (2010) Optimization of the water-insoluble procedures for USP General Chapter Residual Solvents $<467>$. AAPS Pharm. Sci. Tech. 11:994-1004.

Ettre, L. S., C. Welter and B. Kolb (1993) Determination of gasliquid partition coefficients by automatic equilibrium Headspace-gas chromatography utilizing the phase ratio variation method. Chromatographia 35:73-84.

Huie, C. W. (2002) A review of modern sample-preparation techniques for the extraction and analysis of medicinal plants. Anal. Bioanal. Chem. 373:23-30.

Jumepaeng, T., D. L. Luthria and S. Chanthai (2012) The effect of surfactant on headspace single drop microextraction for the determination of some volatile aroma compounds in citronella grass and lemongrass leaves by gas chromatography. Anal. Methods 4:421-428.

Kim, J. H., G. H. Choi, S. J. Lim and B. J. Park (2015) Stability of matrine and oxymatrine from the biopesticide from Sophora flavescens under aquatic and soil environment. Kor. J. Environ. Agric. 34:1-5.

Kolb, B., C. Welter and C. Bichler (1992) Determination of partition coefficients by automatic equilibrium headspace gas chromatography by vapor phase calibration. Chromatographia 34:235-240.

Laus, G., M. Andre, G. Bentivoglio and H. Schottenberger (2009) Ionic liquids as superior solvents for headspace gas chromatography of residual solvents with very low vapor pressure, relevant for pharmaceutical final dosage forms. J. Chroma. A. 1216:6020-6023.

Luzar, A. and D. Chandler (1993) Structure and hydrogen bond dynamics of water-dimethyl sulfoxide mixture by computer simulations. J. Chem. Phys. 98:8160-8173.

Paik, M. K., J. M. Park, J. I. Kim, G. H. Choi, S. Y. Kim, S. M. Hong, G. J. Im, M. K. Hong and J. H. Kim (2011) Analyses of residual alkylbenzenes and its probabilistic risk assessment in Sundried salts. J. Kor. Soc. Appl. Biol. Chem. 54:124127.

Somuramasami, J., Y. C. Wei, E. F. Soliman and A. M. Rustum (2011) Static headspace gas chromatographic method for the determination of low and high boiling residual solvents in Betamethasone valerate. J. Pharma. Biomed. Anal. 54: 242-247.

Teja, A. S., A. K. Gupta, K. Bullock, X. S. Chai and J. Zhu (2001) Henry's constants of methanol in aqueous systems containing salts. Fluid Phase Equilibria 185:265-274.

Urakami, K., A. Higashi, K. Umemoto and M. Godo (2004) Matrix media selection for the determination of residual solvents in pharmaceuticals by static headspace gas chromatography. J. Chroma. A. 1057:203-210.

Ye, C. L., Q. X. Zhou and X. M. Wang (2006) Headspace liquid-phase microextraction using ionic liquid as extractant for the preconcentration of dichlorodiphenyltrichloroethane and its metabolites at trace levels in water samples. Analytica Chimica Acta. 572:165-171.

\title{
Headspace 법을 사용한 유기농업자재 중 잔류 유기용매 분석
}

\author{
최근형 ${ }^{1}$ 공승헌 ${ }^{2} \cdot$ 박병준 ${ }^{1} \cdot$ 문병철 ${ }^{1}$ 김진효 ${ }^{2, *}$
}

1농촌진흥청 국립농업과학원 화학물질안전과, ${ }^{2}$ 경상대학교 농업생명과학연구원 응용생명과학부(BK21 plus)

요 약 본 연구에서는 유기농업자재 중 잔류 휘발성 유기용매의 정성 및 정량분석을 위해 Headspace-GC 분석법 을 matrix 조성을 달리하여 검출능을 중심으로 시험하였다. Headspace sampler내 흡습제처리 혹은 DMSO molar ratio를 증가시키는 방법을 통해 친수성기를 갖는 유기용매의 분석능이 최대 $715 \%$ 향상되었으며, 특히 농자재의 보 조제로 많이 사용되는 계면활성제의 경우 시료 중 농도가 계면활성제의 종류보다 유기용매 분석능에 미치는 영향이 큰 것을 확인할 수 있었다(68.5-179.1\%). 특히 병해충 관리용 유기농업자재의 보조성분 및 함량이 정확히 공개되지 않은 상황에서 유기용매의 함량 정량분석을 위해서는 각각의 분석시료마다 matrix-matched calibration을 통한 정량 분석으로의 접근이 검토되어야 할 것으로 판단된다.

색인어 Headspace, matrix-matched calibration, 유기용매, 유기농업자재, 계면활성제 